\title{
Fresh Water Demand Minimization in Residential Urban
}

\section{Buildings}

\author{
Antonios Saragkas and George Paschalidis \\ Department of Forestry and Natural Environment Management, Eastern Macedonia and Thrace Institute of Technology, Kavala \\ 65404, Greece
}

\begin{abstract}
In the last decades, there is a lot of discussion in many scientific fields, about the high importance of water as a basic element for the existence and the maintenance of life, aiming to the right and proper usage of water in our everyday basic water-needs due to its limited resources and the growing demand. This research deals with simple ways and technological systems applicable in urban residential buildings for the better management of domestic fresh water, as far as its maintenance and sustainability. Main aim of the survey is the effective minimization of urban daily water usage. All measurements of water quantities have estimated in the imperial gallon ( 1 gallon $\approx 4.546$ liter), and in liter ( 1 liter $\approx 0.2$ gallon).
\end{abstract}

Key words: Efficient urban water management, sustainable buildings, water resources sustainability.

\section{Introduction}

Nowadays, many scientists are trying to warn governments about the serious upcoming water shortage in the near future. As we all know from our living experience, the value of water is priceless, and the lack of it could cause enormous problems and dysfunctions in life cycle. Water is a valuable resource, and its sustainability can ensure the existence and the maintenance of any kind of life. Nowadays the main water use sectors are: agricultural, urban, industrial, energy, touristic activities.

Water scarcity is a phenomenon which causes vital problems in many countries. Water scarcity can be defined as a condition in which people lack sufficient water or else do not have access to safe water supplies. Imbalances between availability and demand, the degradation of ground water and surface water quality, interregional and international conflicts, all contributes to water scarcity. Water scarcity has impact in health, hunger, education, poverty [1].

As far as the causes of water scarcity, we must refer

Corresponding author: Antonios Saragkas, master, research field: management in water resources of the mediterranean. E-mail: asara494@gmail.com. to the fact that the global quantities of water in our planet does not increase or decrease. Water quantities remain the same, but they are located in different storage areas during different time periods. There are three main important causes of water scarcity: The explosive growth of demand [2], the climate change [3], the degradation of many of the available fresh water quantities of the planet mainly due to human activities.

The first priority for every nation in the world must be the access in freshwater supplies for their populations. However, keeping stable the water supplies are very hard to handle by many countries, as the water-related risks increasing year by year. According to a 2013 project of the Aqueduct Water Resources Institute (WRI's Aqueduct) which evaluate, map and score water risks in 100 river basins, indicates that 36 countries is under "extremely high" levels of baseline water stress. This shows that more than 80 percent of the water resources needful for the agricultural, domestic, and industrial sector are withdrawn in annual level, leaving people in businesses, farms, and communities vulnerable and helpless to the scarcity. Also a more comprehensive 
analysis indicates that 37 percent of all countries taken part to the research, are under high to extremely high baseline water stress. This problem can affect in a negative way a country's stability as far as economy, environment, and communities [4]. Moreover, this project indicated that lower limits than 1,000 $\mathrm{m}^{3} /$ inhabitant (in annual rate) correspond respectively to countries and cities with high water stress and water scarcity. In annual level, $1,000 \mathrm{~m}^{3}$ of water per individual can be considered the threshold to sustain life, and also can ensure the agricultural production in countries and cities with climates that require irrigation for agriculture [5].

The huge problem of insufficient water management is the main reason for the increase of water scarcity levels. The sector of agriculture reaches the first positions of water-need in any country. The contamination of aquifers mainly from the usage of pesticides and with no control proprietary drillings has led to the reduction of the available water. In addition, the population grows and the need for more goods maximizes. Moreover the fact that half the population of big countries live in a few large cities increase the already big problem of sufficient water in the keep growing urban cities. Furthermore, as far as the domestic use of water under daily urban conditions, although the estimates vary, each individual uses approximately 3,637 to 4,546 lt. (80-100 gallons) per day [6]. The most significant thing is that the largest amount of our water use goes to the flush of the toilet. In addition, the use of washing machines reaches the second position and the third position is occupied by the use of shower. Important role to the domestic distribution of waste water have the possible leaks of any pipeline system be it accidentally or deliberately.

\section{Materials}

There are several technological methods and simple suggestions for sustainable use of water in residential urban buildings leading to a sustainable use of our available water quantities.
2.1. Developing Water Conservation Public Awareness, the First Priority for Each Municipality in Any City

The water conservation public awareness has one specific role: the understanding of the need to use water with efficiently ways at all stages from capture to consumption, in order to succeed change in attitudes and behavior of people as far as the water management and use [7].

\subsection{Simple Ways and Tips to Help Conserve Water Indoors and Outdoors in Houses}

There are many ways to conserve water in daily basis, most of them is simple and non-expensive minimizing significant amounts of water resulting positive in the sustainability of water resources and in our home-finance, such as continuous checking for possible leaks in faucets and pipes, minimizing the use of toilet's flush, smart using of faucet, planting drought-resistance lawn e.g. [8].

\subsection{Applying Xeriscaping in Home Gardens}

"Xeriscaping" is called the utilities of landscaping and gardening which aim in the minimization or elimination of water supplemental for their irrigation. It is very common habit the implementation of xeriscaping in areas that have lack of accessible, plentiful and reliable sources of fresh water. Xeriscaping consists a similar type of traditional gardening. It emphasizes in the selection of plants that have the ability to survive with very few water amounts, not necessarily native kinds of plants [9].

\subsection{Devices That Reduce the Amount of Water-use in Residential Buildings}

When water shortage became a serious problem for the survival of many cities in some countries, technology discover devices which in combination with the proper environmental sensitization can reduce the total daily water use in residential buildings, saving enormous quantities of useful water, and the most important is that they are applicable in any kind 
of buildings. These devises are smart meters, low flow faucets, dual flush toilets, foot-pedal faucets, the use of showers, the use of front-loading washers, the dishwashers, photocell faucets.

\subsection{Proper Management to the Water Supply Distribution System}

Large quantities of available clean water lost in global level due to problems in the water supply distribution system. The leak problems in public water supply systems leads in loss of clean drinking water which resulted in the need for more energy and material resources for the operations of abstraction, transportation and treatment. Also, it results in second matter at economic loss as well, in the form of, damages to the pipe networks, public health concerns as it could increases the risk of water contamination by dangerous microorganisms, and the possibility of a future pollution of the environment. The technology has created systems and devises which can maximize the efficiency of a water distribution pipeline system by reducing possible leaks. There are several leak detection practices and techniques [10].

\subsection{Recycling/Reuse of Waste Water Streams}

The waste waters that discharged from buildings after their usage are divided in 2 categories, the waste greywaters (or sullage waters) and the waste blackwaters (or sewage waters). In order to succeed recycling/reuse of waste waters in buildings required a dual plumbing establishment in the buildings for the waste waters separation in waste greywaters and waste blackwaters. The greywater streams are very low-rate dirt water streams and can be utilized into a series of water-needed actions but first it must separate from the black water streams. For the implementation it required foresight before and during the building's construction. Moreover, in areas where greywater systems are allowed, water that does not contain human wastes or dangerous substances for health, may be reused for the daily usage of toilet flushing and outdoor irrigation of non-food plants.

\subsection{Rainwater Harvesting and Utilization}

A decentralized, environmentally sound technological solution is the rainwater harvesting and utilization. Rainwater harvesting is called the technology which used for collecting and storing rainwater for human daily use. This can implement with applications in rooftops, land surfaces, rock catchments [11]. All the applications comprise simple techniques, for example jars and pots as well as engineered techniques. Rainwater harvesting consist a significant water source in regions with significant rainfall but without any kind of conventional, centralized supply system. In addition, is a good option in regions with no good quality of fresh surface water or ground water. Appropriate applicable methods of rainwater harvesting technology are required for the utilization of rainwater as a water resource [12].

\subsection{Sustainable Design Buildings and Integrated Urban Water Management}

According to the EPA [13], green buildings are those utilized in the creation of their practical use to form structures and processes that are environmentally responsible and efficient management of resources throughout the life of a building, the location and design, construction, operation, maintenance, renovation and demolition. This practice complements the principles of classic design buildings for economy recovery, strength and comfort. Green building is therefore a sustainable building or else a high performance building. In ecology, sustainability is how technical systems endure and remain diverse and productive. Thus, the sustainable design buildings consist significant depended constructions of the right and efficient integrated urban water management.

\section{Results and Discussion}

According to the estimates of the World Health 
Organization a man needs not less or higher than 50 litre (10.1 gallons) of water per day for all they needs including cooking, personal hygiene, and drinking in order to avoid diseases and to retain efficiency. Moreover, from this initial amount only 20 litre (4.4 gallon) per day are needed for the preparation of meals and drinking [14]. Furthermore, we must refer to the fact, that as the essential amount for a healthy living is about 50 litre (10.1 gallons) per day, many people in Africa must handle all these basic needs with only 20 litre (4.4 gallons) per day and a very important estimation shows that this specific amount of water run if we use our bath-shower just for 1.5 minutes [15].

\section{Conclusions}

According to scientific estimates, by 2025, approximately 1,800 million people will be living in countries or regions with conditions of absolute water scarcity, and two-thirds of the world population could be in the level of water stress [16]. In addition, $60 \%$ of the world's population will be urbanized by 2030 [17].

Furthermore, water use has been growing at more than twice the rate of population increase mainly in the last century. Although there is no global water scarcity, an increasing significant number of regions in many countries periodically face water shortage problems. Unfortunately, the situation will be exacerbated as the rapidly growing urban areas will add further pressure on the already heavy pressured available water resources.

Nowadays, all we can understand that is emergency to have sustainable water management in order to protect the water environment and to reach current and future human demand. Moreover, the cities of tomorrow must be planned in order to avoid the urbanization negative effects in the environment and special in water resources. In order to succeed a secure and sustainable water future, the efficiency levels of the existing current water supply and the water usage is necessary to improved.
The technology has come a long way making devices that can effectively help a most cost-effective minimization of water. All these water economic devices and systems are used in many regions with water stress issues in countries such as Australia, U.S.A., Africa and Japan e.g. having positive effects and improving the existing suffering water conditions. However, only technology couldn't be a solution, because if any individual who handle these systems and devices, have not understood the importance of economic and rational management of water, no positive results would come.

Unfortunately, so far drinking water is dwindling mainly by faulty and bad management actions. The appropriate utilities and creating an operational plan on the distribution and for the rational use of water is our only chance in order to gain benefits and improve the quality of our daily life. For these reasons, it is important for society to be efficiently active and environmentally sensitive in order to preserve the quality of water and therefore of life.

\section{Acknowledgements}

The authors thanks their families for their support as well as all the individuals who provide them with any kind of help and support.

\section{References}

[1] Water Issues in Developing Countries. 2014. "Water Issues in Developing Countries." Accessed August 20, 2014.

http://en.wikipedia.org/wiki/Water_issues_in_developing countries.

[2] Vairavamoorthi, K., Gorantiwar, D. S., and Pathirana, A. 2008. "Managing Urban Water Supplies in Developing Countries-climate Change and Water Scarcity Scenarios." Physics and Chemistry of the Earth 33: 330-339.

[3] Jones, P. D., and Moberg, A. 2003. "Hemispheric and Large-scale Surface Air Temperature Variations: An Extensive Revision and an Update to 2001.” Journal of Climate 16: 206-223.

[4] World Resources Institute. 2014. "World's 36 Most Water-Stressed Countries." Accessed September 15, 2014.

http://www.wri.org/blog/2013/12/world\%E2\%80\%99s-3 
6-most-water-stressed-countries.

[5] Food and Agriculture Organization of the United Nations. 2014. “Aquastat." Accessed November 20, 2014. http://www.fao.org/nr/water/aquastat/main/index.stm.

[6] USGS. 2014. "The Water Science School, Water Questions and Answers." Accessed December 20, 2014. http://water.usgs.gov/edu/qa-home-percapita.html.

[7] UNESCAP. 2002. Public Awareness on Water Conservation and Water Efficiency. The United Nations: UNESCAP.

[8] Eartheasy. 2014. "25 Ways to Conserve Water in the Home and Yard." Accessed November 27, 2014. http://eartheasy.com/live_water_saving.htm.

[9] Xeriscaping. 2014. "Xeriscaping." Accessed December 25, 2014. http://en.wikipedia.org/wiki/Xeriscaping.

[10] Pilcher, R. 2003. Leak Detection Practices and Techniques: A Practical Approach. IWA: Water 21 by the IWA WATER Loss Task Force.

[11] Harvested Rainwater. 2015. "Sustainable Sources, 21 Years of Online Green Building Information.” Accessed October 30 ,

2015. http://rainwater.sustainablesources.com/.
[12] Global Development Research Center (GDRC). Rainwater Harvesting and Utilization. An Environmentally Sound Approach for Sustainable Urban Water Management: An Introductory Guide for Decision-Makers. JAPAN: GDRC.

[13] U.S. Environmental Protection Agency. 2015. "EPA Green Buildings." Accessed January 10, 2015. http://www.epa.gov/oaintrnt/projects/.

[14] Reed Bob., and Reed Brian. 2013. Technical Notes on Drinking-water, Sanitation and Hygiene in Emergencies. The International: World Health Organization.

[15] Institute Water for Africa. 2014. "Water Consumption." Accessed October 16, 2014. http://www. water-for-africa.org/en/water-consumption.html.

[16] United Nations Water. 2014. "International Decade for Action, Water for Life, 2005-2015."' Accessed November 22 , 2014. http://www.un.org/waterforlifedecade/scarcity.html.

[17] United Nations Water. 2014. "World Water Day, 2013." Accessed December 25, 2014. http://www.unwater.org/water-cooperation-2013/water-c ooperation/facts-and-figures/en/. 